\title{
LOS VIAJES Y TRABAJOS DE MANUEL IRADIER EN ÁFRICA: GÉNERO E HIBRIDISMO TEXTUAL EN EL RELATO DE VIAJES EN EL SIGLO XIX*
}

\begin{abstract}
Álvaro Llosa SANZ
University of Nevada, Reno

\section{El RELATO DE VIAJES COMO GÉNERO LITERARIO Y SU HIBRIDISMO TEXTUAL}

Carrizo Rueda (1995) propone como característica definitoria del relato de viajes el bifrontismo entre dos aspectos siempre presentes en este género: el documental y el literario, conectados por una dominante técnica descriptiva que es la que acaba por constituir y desarrollar un itinerario singular donde cada elemento descrito (objetos, personas, paisajes, acciones) constituye un paso esencial y necesario en la aventura viajera. De hecho, esta aventura viajera se constituye por sí misma en ese seguir los pasos itinerantes de una a otra descripción, hasta construir una red de informaciones variadas y acciones diversas donde no importa tanto el desenlace como el desarrollo del relato.

Así, lo documental y lo literario se integran perfectamente en el relato de viajes. Información y estética se aúnan en diversos grados para producir una obra que, en opinión de Villar Dégano (1995), se adscribiría a la paraliteratura y, como tal, participaría de una naturaleza híbrida en la que la mezcla de intenciones e intereses (utilidad y goce, ocio y negocio) camina paralela al uso de diversos géneros, añadimos, pertenecientes tanto a la esfera de lo documental como a la literaria. De este modo, cercanos a la miscelánea, pero con el itinerario del yo como firme hilo conductor o aglutinador de experiencias en torno a diferentes espacios, los libros o relatos de viajes se nos presentan como uno de los géneros de mayor encrucijada formal, puesto que en él confluyen otros géneros diversos.

Según esto, vamos a centrarnos en el análisis de un relato concreto que nos llevará a un escenario geográfico colonial del siglo XIX español a través de una de las expediciones más representativas de la época, y que se con-
\end{abstract}

* Agradezco el apoyo y consejos que durante la elaboración de este trabajo me brindó Ana María Freire (UNED).

Rlit, LXVII, 134 (2005), 557-584 
virtió a través de la publicación de sus notas, apuntes, mediciones, dibujos, experiencias personales, documentos, etcétera, en uno de los libros de viaje sobre el África ecuatorial española más interesantes y completos de nuestra literatura.

\section{LOS VIAJES Y TRABAJOS DE MANUEL IRADIER EN ÁFRICA}

\section{El africanismo español en el siglo XIX}

En la época de Carlos V la conquista de plazas africanas había sido una mera cuestión geoestratégica, si bien la reina Isabel había dejado testamentariamente su deseo de proseguir la conquista norteafricana amparada por razones religiosas. Esta situación se mantuvo hasta bien avanzado el siglo XVIII, puesto que España estaba embebida en la Conquista de Ultramar (Reguera Rodríguez 2002: 25-26; Pedraz Marcos 2000: 39-40). Sólo a principios de siglo XIX Godoy cuenta con la colaboración de Domingo Badía, conocido en África por Alí Bey, para espiar y recabar información sobre las costas norteafricanas con visos de una posible guerra y beneficios comerciales, pero Carlos IV impidió al fin la campaña deseada. Desde ese momento, en España comenzará un interés por ese continente «deshabitado» debido a la precaria situación internacional española: fundamentalmente a la emancipación de las colonias americanas, la alianza entre Portugal e Inglaterra para crear una potencia oceánica y el desembarco argelino por los franceses, con la intención de desplazarse al África más occidental. Los problemas internos y la lucha de clases generada en la política interior española hicieron ver en la desastrosa situación exterior una imagen del estado del país, y así el africanismo se convirtió en el siglo XIX en un asunto ideológico en el que África se convierte en «destino manifiesto» tras la conquista ultramarina, y se urge desde los grandes grupos de poder a realizar campañas que en opinión de muchos salvarían y regenerarían la política interior española. España se proyecta en el continente africano con una misión nacional que invoca para los nacionalistas un espíritu de cruzada patriótico y con la justificación típica del eurocentrismo decimonónico de una expansión colonial sujeta, no a razones religiosas, sino civilizadoras (Reguera Rodríguez 2002).

Con esta última pretensión se habían justificado ya las acciones colonialistas de las principales potencias europeas y en torno a estas actividades nacen las Sociedades Geográficas, entidades privadas cercanas al poder y conformadas por variados profesionales que en un principio (la primera institución importante fue la Société Géographique de París en 1821) buscaban el estudio de la Tierra en cualquier aspecto geográfico y que a partir de 1870, momento de su multiplicación en todo el orbe, colaborarán con los intereses de los estados y sus fines militares-colonialistas gracias a las informaciones obtenidas mediante las expediciones realizadas (Rodríguez Esteban 2002). De 
las más de doscientas sociedades y asociaciones que se fundan en cuarenta y cinco países hasta la Segunda Guerra Mundial, casi un centenar de ellas lo hacen en el período 1871-1890 (Rodríguez Esteban 2002: 59 y 63). En España, Manuel Iradier funda la primera asociación africanista, de carácter local, en 1872 (Sociedad Euscara La Exploradora) y sólo en 1876 queda instituida la Sociedad Geográfica de Madrid liderada por Francisco Coello, que se unirá a la que fue definitiva institucionalización del africanismo español: la Sociedad Española de Africanistas y Colonialistas (1884).

\section{El africanismo español y el Golfo de Guinea}

Ya en 1778, mediante el Tratado del Pardo firmado con los portugueses, Floridablanca logra la cesión en régimen de soberanía de la costa guineana (básicamente islas de Annobón y Fernando Póo) que hasta entonces pertenecía a Portugal. España usó estos territorios con fines comerciales, para los que tenía la exclusividad; fundamentalmente se utilizaban para capturar, guardar y embarcar esclavos con destino a las colonias americanas (Pedraz Marcos 2000: 39; Carrasco González 2002: 119). Sin embargo, debido a la evolución de los ideales en derechos humanos, España e Inglaterra acuerdan en 1817 abolir la trata de esclavos, y la zona queda inservible y sólo conservada durante tanto tiempo por cuestión de orgullo nacional. En palabras de Carrasco González (2002: 119): «Las posesiones se quedan inútiles para los gobiernos españoles. No sirven ya para la captura y comercio humano, están alejadas de las rutas de navegación con las colonias americanas, no tienen interés estratégico para la defensa de territorio alguno, no son necesarios sus productos porque el mercado no los demanda y constituyen un lugar insalubre capaz de acabar con la vida del más sano de los europeos». Fue un territorio nominal, sin coste alguno, en el que la ausencia de un presupuesto y una política coherente de exploración y explotación impidieron una ocupación efectiva (Carrasco González 2002: 119 y 127). Esta indolencia es la que provocó desde 1826 hasta 1841 una disputa con Inglaterra en la que España cedió el gobierno de los territorios a los ingleses y hubo de retractarse ante la violenta reacción de la opinión pública (Pedraz Marcos 2000: 40-41). En ese período, no obstante, los ingleses establecieron una base en Santa Isabel (Clarence) y aprovechando el tratado antiesclavista, controlaban e impedían el comercio de los mercantes españoles que se dirigían a la zona (Castro Antolín 2002: 115). En 1842 una expedición gubernativa dirigida por José Lerena logra dar el primer estatuto legal para Guinea y son numerosas las adhesiones indígenas a territorio español; Nicolás Manterola establece en 1845 los límites de la zona continental, en acuerdo con los franceses, y con apenas una guarnición estable, la zona apenas recibe otros expedicionarios (1854-1855: Manuel Rafael de Vargas; 1855-1856: el jesuita Miguel Martínez 
Sanz), que intentan instaurar sin éxito planes comerciales o evangelizadores para la zona, hasta la llegada de Carlos Chacón en 1858 como primer gobernador español en Fernando Póo, principal isla de la costa guineana (Carrasco González 2002: 120; Pedraz Marcos 2000: 42). A pesar de que en esos años hubo cierto interés (concurso estatal de por medio en 1842) y variados proyectos colonizadores para la zona (propuestos por comerciantes e incluso un famoso negrero), ninguno prosperó por la falta de apoyo gubernamental en un territorio que requería mayor seguridad e inversión (Castro Antolín 2002: 113-114; Pedraz Marcos 2000: 326-330). Desde 1858, no obstante, el control es superior, las anexiones son mayores y se discute en España el interés y las posibilidades comerciales de la zona, que cuenta con defensores y retractores. En cualquier caso, la constante falta de ocupación efectiva provocó que, por resolución de la Conferencia de Berlín (1885) y por el tratado franco-español de 1900 España se quedara con una décima parte del territorio que hasta entonces le había correspondido y que apenas había explotado (Carrasco González 2002: 121 y ss.).

\section{Manuel Iradier, La Exploradora y su misión colonial}

A las expediciones de Manuel Iradier, Amado Osorio y Juan Montes de Oca se debe lo poco que España conservó de Guinea tras el tratado francoespañol de 1900 (González Echegaray 2002: 330). Manuel Iradier y Bulfy (1854-1911), vitoriano, hombre emprendedor con notable poca fortuna en su vida, licenciado en Filosofía y Letras, soldado, inquieto y romántico explorador, conferencista, inventor, masón, y, tras sus dos expediciones, trabajador en diversos puestos con los que mantener a su familia (Pedraz Marcos 2000: 90-94; Martínez Salazar 1993), representa en una misma persona el carácter de las expediciones decimonónicas en África, que «eran a la vez geográficas, militares y científicas» (González Echegaray 2002: 329). En Iradier «se juntan el geógrafo incansable, el representante de España (aunque a título particular) y el científico curioso y documentado» (Íbid.: 330).

En 1874 ofrece una conferencia por la que queda fundada la primera asociación africanista española; en ella se muestra la intención de explorar toda África, proyecto que por consejo del gran explorador Stanley se reduce a un recorrido hacia el interior desde la costa guineana. Sierra Delgade (2002: 319) describe muy bien el periplo de esta primera aventura, realizada casi en solitario y con un presupuesto ridículo, sin apoyo gubernamental:

\footnotetext{
Así, en diciembre de 1874, poco antes de la Navidad y apoyado por la sociedad local de Vitoria La Viajera, que luego se llamó La Exploradora, emprende su viaje el licenciado vitoriano con la idea de saber si desde la costa occidental, frente a las posesiones españolas del Golfo de Guinea hay un punto accesible para el interior. (...) Iradier embarca en el Loanda rumbo a la Bahía de
} 
Corisco con una carta para el rey Convenyamango, y a partir de aquí pasa al interior donde toma contacto con los pueblos observando sus costumbres, destacando su habilidad en el manejo del hierro. Con el vapor La Esperanza recorrerá las costas al norte de la bahía de Corisco. En sus desplazamientos parte del río Muni, reconociendo en la aldea de Combo a los pueblos vicos y llega hasta el río Utamboni en la Sierra de Cristal, viendo por vez primera a los pamues o fang en $B a$, la zona más oriental del continente».

Regresa enfermo en 1877, tras un recorrido de 1.879 kilómetros, con un diario y numerosos datos y mediciones, de los que se harán eco la Sociedad Geográfica; no satisfecho con ello, y a pesar de las dificultades para encontrar nuevos apoyos económicos e institucionales, en 1884 inicia, apoyado por la recién creada Sociedad Africanista y con la misión de anexionar nuevos territorios del interior guineano (Pedraz Marcos 2000: 332-342), una segunda expedición (ibíd.: 343-349) que habrá de abandonar pronto por enfermedad y que dejará en manos de su compañero Osorio y el gobernador de Fernando Póo, Montes de Oca, quienes habrán de verse expuestos a los abusos que franceses y alemanes están llevando a cabo sobre posesiones españolas. Sin embargo, el 20 de mayo de 1886, finalizado el viaje, los tres expedicionarios son invitados a una conferencia solemne en el Ateneo durante la cual exponen sus experiencias y resultados (Sierra Delgade 2002: 323). Y a pesar del momentáneo interés que causa esta región africana, por las razones que ya hemos expuesto, Guinea seguirá sin ser explotada adecuadamente, y Manuel Iradier debe renunciar, con desilusión, a la posibilidad de liderar nuevas expediciones; dedicado a diversos trabajos en la península su vida se desvanece con un debilitamiento de salud progresivo al que le condenó, como a toda su familia, la herencia dejada por las terribles fiebres de las costa guineana.

\section{HIBRIDISMO DE GÉNEROS EN 'ÁfRICA'}

Fruto y compendio de sus dos expediciones es el volumen (dividido en dos tomos) titulado África. Viajes y trabajos de la Asociación Eúskara La Exploradora (1887), impreso en Vitoria por la Imprenta Vda. e Hijos de Iturbe. En él aborda las principales experiencias y dificultades de ambos viajes, y detalla numerosos datos.

El primer tomo está dedicado a la narración de las dos expediciones y se divide en cuatro partes, dos para cada viaje:

1. ${ }^{a}$ parte: Costa Occidental de África: narra la preparación del viaje hasta la llegada a Camarones, punto de partida de la verdadera expedición.

2. ${ }^{a}$ parte: El País del Muni: narra todas las experiencias de la expedición por el interior de Guinea.

3. ${ }^{a}$ parte: La Exploradora-Sociedad de Africanistas: origen, planes, propuestas, dificultades y contratiempos en la preparación del segundo viaje. 
4. ${ }^{a}$ parte: Ocupación del Muni: narración de las experiencias, regreso e implicaciones institucionales de esta segunda expedición.

El segundo tomo se dedica a repasar metódicamente diferentes ámbitos de la geografía física y humana de las tierras visitadas, y lo divide en tres partes:

1. ${ }^{a}$ parte: El País del Muni: descripción sistemática de aspectos de geografía física de la región.

2. ${ }^{a}$ parte: El habitante del Muni: descripción sistemática de aspectos de geografía humana de la región.

3. ${ }^{a}$ parte: Derechos de España: documentos que acreditan los derechos legales de España sobre zonas que reclamaba Francia.

Esta somera descripción del esqueleto del libro nos indica las posibilidades intrínsecas de un fértil hibridismo en géneros en la obra. Por otra parte, para nuestro trabajo, como no existe actualmente una clasificación única, constante, de géneros y tipología de textos, cuestión controvertida donde las haya, y como no se trata aquí de discutir clasificaciones, sino de mostrar fundamentalmente la variedad y diversidad de formas textuales que conforman la obra, atenderemos a categorías tradicionalmente aceptadas y usadas, especificando luego en lo posible las variedades genéricas a que pueda adscribirse el fragmento seleccionado en cada caso. Eso sí, partamos, ya que nuestra hipótesis inicial así lo disponía, de la dimensión bicéfala del relato de viajes, su documentalismo y su literariedad, lo que nos lleva inmediatamente a diseñar dos grandes grupos desde los que desglosar y organizar los sucesivos géneros: el documental y el literario.

Como fin de estos párrafos de indicaciones preliminares, y para enlazar definitivamente con nuestro relato, observemos un detalle que resulta de interés para nuestro planteamiento, pues ya desde los objetivos que presiden los viajes del autor se intuye la necesidad posterior (al hacer del viaje palabra) de utilizar una variedad de géneros que den forma textual completa a los diversos resultados y experiencias de las expediciones, como se podría deducir del siguiente fragmento perteneciente a África (Iradier 1887: 252), extracto de otra conferencia leída en Vitoria por Iradier en 1879 para acaparar interesados en apoyar una segunda expedición:

La Exploradora al hacer este viaje comprende en su misión las observaciones astronómicas, las meteorológicas, la reunión de colecciones de botánica, de zoología y de geología, la formación de mapas de países recorridos, la redacción de vocabularios y gramáticas de los indígenas, las observaciones etnológicas, la redacción de las relaciones de los viajeros del país, la formación de un álbum fotográfico de paisajes, pueblos y tipos, la formación de un Diario que relate todos los sucesos y todas las observaciones científicas, industriales, comerciales y demás que conduzcan al conocimiento completo del país, y que sean de interés general. 


\section{Géneros documentales}

a) Textos administrativos y legales: informes y proyectos, cartas oficiales, solicitudes, telegramas, estatutos, presupuestos, contratos y certificados

Iradier presenta al comienzo de su parte tercera del primer tomo algunos documentos que precedieron a su segunda expedición, cuyas dificultades de organización casi superaron a las de su realización efectiva. Entre estos documentos destaca un somero plan o proyecto (I, cap. XLIII, pp. 250-252) al que acompaña luego una idea del plan (I, cap. XLIII, pp. 261-264); mientras que el primero traslada con cierto esquematismo la propuesta expedicionaria, su itinerario y los recursos necesarios, la segunda transmite con cierta vehemencia los ideales de La Exploradora puestos en tal empresa, así como su filosofía y la idoneidad de la agrupación para llevar a cabo dicha expedición. Estos dos textos no dejan de coincidir en ser informes sucintos de estilo pulcro, directo y preciso con el fin de mostrar el análisis de una situación o un plan de acción. Veamos un fragmento de ambos textos:

El punto de partida de dicho itinerario será la bahía de Corisco, cuyos habitantes me tienen ofrecido apoyo, y cuyo terreno se eleva gradualmente; atraviesa la cordillera Ukudí-masei (Sierra de Cristal) dirigiéndose al volcán Onyiko que está en actividad y después buscará al N.E. el curso del río Eyo cuyo curso seguirá hasta encontrar el Ogoué, se dirigirá después al E. hasta tocar en el lago Niansa-Mvutan de donde torcerá al N.O. hasta el Kubanda y lago Liba siguiendo el río del mismo nombre y saliendo por el río Camarones.

Comprende este itinerario en distancia aparente 2.700 millas y en distancia aproximada 3.600 millas. Se empezará la exploración en el mes de Mayo o Junio.

La región del África central de occidente, campo de los estudios de LA EXPLORADORA, se diferencia mucho en condiciones de las de Oriente. En ésta, los indígenas forman Estados extensos y gracias a los esfuerzos de los árabes, están en relación constante con la costa, circulando los productos de la industria europea con gran profusión. En la región occidental, los habitantes forman Estado pequeños que no se relacionan con los establecimientos europeos; el espíritu de comercio no está suficientemente desarrollado, y las condiciones generales son enteramente opuestas a las de otra zona. Por eso aquí es más conveniente que en ninguna otra parte empezar la obra civilizadora desde la costa misma y no dar un paso al interior sin completa seguridad de que el camino no será interceptado.

También en ese mismo capítulo aparecen los informes que son respuestas oficiales (de la Comisión Ejecutiva de la Exploradora y de la Sociedad Geográfica) al plan antes citado (I, cap. XLIII, pp. 252-256 y 259-261), en 
las que se responde en términos parecidos sobre el interés de la empresa y su utilidad para el país.

Toda la documentación fue enviada a través de una solicitud al Sr. Ministro de Ultramar, que Iradier transcribe también, y de la cual, por ser un tipo de texto legal bien definido, extractamos aquí (I, cap. XLIII, pp. 258-259):

\section{Excmo. Sr. Ministro de Ultramar}

Excmo. Sr.

La EXPLORADORA, asociación euskara para la exploración del África central a V.E. con el debido respeto expone: Que desde su fundación en 1868, la asociación que tengo la honra de presidir ha venido realizando numerosos trabajos y activa propaganda para la consecución del alto y civilizador objeto para que fuera establecida. (...) ... trata de enviar una nueva expedición exploradora cuyos gastos están presupuestados en veinte mil pesetas según puede verse por la relación que se acompaña para lo cual la Asociación sólo necesita recabar la protección oficial y los auxilios indispensables para llevar a cabo sus propósitos. (...) ... acude a V.E. esperando de su amor a la ciencia, de su claro criterio y de su reconocido patriotismo, se dignará acoger benévolamente este proyecto... (...) En virtud de lo expuesto LA EXPLORADORA:

Suplica a V.E. se digne otorgarle, para el envío de una comisión exploradora al África central, la protección y los recursos materiales que estime conducentes.

Vitoria, 24 de abril de 1881.

Por La EXPLORADORA

MANUEL IRADIER Presidente

Por último, como material accesorio enviaron la copia de algunas cartas de adhesión (I, cap. XLIII, pp. 264-274) al proyecto, pequeñas notas remitidas a La Exploradora por diversos personajes de prestigio internacionales. Repletos de fórmulas y adjetivos preestablecidos, y de estilo cortés y laudatorio, como corresponde a estos textos de recomendación, las notas suenan así:

Madrid, 18 de junio de 1880.

Sr. Presidente de «La Exploradora».

...Deseo vivamente que mi cooperación pueda ser de alguna utilidad y sobre todo que se vean realizados los deseos abrigados al organizar esa Asociación ya que en la Africana no ha sido posible por falta de recursos, proteger sus intenciones de usted que con tanto desinterés se halla pronto a sacrificarse en honor de la Ciencia y del buen nombre de nuestro país...

Francisco DE COEllo, Presidente de la Sociedad Geográfica de Madrid. 
Madrid, 3 de Abril de 1880.

...Acepto con gusto y entusiasmo el nombramiento de Socio Honorario de «La Exploradora» y para su ejecución me suscribo por una vez con cuatro mil reales que puede el Tesorero girar a mi cargo...

El MARQuÉS DE URQUiJo

(Costa de África) Gabón, 31 Marzo 1881.

Sr. Presidente de «La Exploradora».

...Tengo el honor de informar a usted que estoy a la disposición de «La Exploradora»... No faltará de dar a la Asociación todas noticias importantes del país para que pueda desarrollar su plan grandioso...

EMIL SCHULCE, Cónsul de Alemania

No pueden faltar, por breves que sean, documentos legales de tipo económico, es decir, varios presupuestos, como las suscripciones para la segunda expedición (I, cap. XIV, pp. 287-289) y el presupuesto final de dicha expedición (I, cap. XIV, p. 289), cuyo borrador se había ya presentado en el plan, algunos años antes (I, cap. XLIII, p. 251). En estos documentos se señala el concepto y su gasto, y finalmente la suma total.

Una vez iniciada la expedición, año 1884, según Iradier y su compañía llegaban a las aldeas, extendían una serie de documentos ante los jefes o reyes de cada población por los cuales se aseguraban su anexión como colonias españolas. Al final del segundo tomo, en la parte dedicada a los derechos de España, aparecen estos documentos administrativos de suma importancia en la colonización guineana de nuestro país.

Por una parte, estaban los certificados (II, cap. XVIII, pp. 692-693) que se entregaban a los jefes sometidos, en los que se los nombraba gobernadores:

Don Bernabé Jiménez Blázquez, Notario habilitado de Santa Isabel de Fernando Póo y todas sus dependencias. -Certifico: que D. Manuel Iradier y Bulfy y D. Amadeo Osorio y Zabala, como Delegados de la Sociedad Española de Africanistas y colonistas, residente en Madrid, y en virtud de las facultades que les han sido conferidas y del contrato celebrado en el día de hoy con el jefe del pueblo de... situado en... declararon propiedad de dicha Sociedad de africanistas todo el territorio comprendido bajo la autoridad del dicho jefe y nombraron al mismo gobernador político de dicho territorio, asignando a él y a todos los que le sucedan en el mando, el sueldo anual de... pesetas, quedando obligados él y todos sus sucesores a no arbolar otro pabellón que el español y a no acatar otras leyes que las de dicha Nación de España a que pertenecen.(Siguen la fecha, las firmas y los sellos).

El certificado a menudo verificaba una situación que previamente se había legalizado mediante un contrato (II, cap. XVIII, pp. 693-694), del que Iradier expone un modelo similar al establecido con los jefes indígenas para 
la anexión de territorios. En él se ratifica la anexión, el nombramiento de gobernador español al jefe indígena y sus obligaciones con su nueva patria. También copiamos un extracto de este documento, que era la única prueba internacional de que aquellas tierras eran españolas; en él se demuestra también lo que se esperaba de los nuevos súbditos:

(...) El... manifestó ser el único jefe del pueblo y territorio citado, por herencia de sus padres y, conviniendo a los padres del dicente y al bien de sus gobernados gozar de las ventajas de los súbditos españoles, dijo: Que se coloca bajo la protección de dicha Sociedad de Africanistas y Colonistas, comprometiéndose, en su virtud, a no arbolar y a no permitir que se arbole en su territorio otro pabellón que el español, así como a no acatar otras leyes, que las de dicha Nación; y declara desde ahora y para siempre nulo y de ningún valor cualquier acto que el declarante o alguno de sus sucesores otorgase o ejecutase, encaminado a ceder a otra Sociedad particular o gobierno, todo o parte del territorio soberanía que en él ejerce.

En fin, sabemos ya que Iradier hubo de retirarse en mitad de la expedición por problemas de salud, dejando a Osorio el liderazgo de la misión. «Destrozado, enfermo, con el estómago perdido, con el hígado infartado, víctima de una fiebre cuotidiana», el 20 de diciembre de 1884 alcanzaba la costa tinerfeña y enviaba un telegrama o despacho oficial por cable (I, cap. XLIX, p. 329), en ese típico estilo cortante y casi sin verbos, que adjunta como una prueba más de su aventura, ya tocando el fin de la narración:

Obtenido Sociedad catorce mil kilómetros cuadrados territorio interior frente Corisco incluso Sierra Cristal. Pactado diez tribus. No posible más en latitud por evitar conflicto internacional y en longitud por fiebres. País gran porvenir. Osorio queda estación con recursos.-IRADIER

Por último, se podría citar el género legal de defensa que Iradier practica en los capítulos L del tomo primero y XIX del segundo, donde responde con un estilo recio y contundentes recursos retóricos a ciertas cuestiones en que su trabajo ha sido cuestionado.

b) Textos científicos: descripciones, ensayos, clasificaciones, tablas, resumen, cronología

Cada vez que llega a un lugar nuevo y, por tanto, desconocido, Iradier comenta someramente la información que tiene. Primero avista el lugar y lo describe tal como surge ante la mirada. Luego ofrece una descripción geográfica más o menos extensa con lo más destacado y por fin narra lo que allí le aconteció. Veamos ahora una de estas descripciones, donde con precisión y agilidad ofrece un rápido repaso a la geografía general de Gambia (I, cap. VII, p. 41): 
La vista que tenía delante puede describirse en esta forma: una faja de arena sobre la que se extendían varias casas cuadradas blancas de uno a dos pisos, entre ellas algunos árboles que producían grata sombra, un cielo azul, el río reflejando el cielo y balanceándose en las aguas una barca italiana, dos buques franceses, un norteamericano y una lancha cañonera.

Gambia forma una colonia inglesa de 179 kilómetros cuadrados con 14.190 habitantes de los que 7.306 son varones y 6.884 son hembras. Su comercio es bastante considerable importando por valor de más de 90.000 libras esterlinas (2.160.000 pesetas). Y exportando unas 88.000 libras esterlinas $(2.112 .000$ pesetas). La población más importante es Bathurst en la isla de Santa María, pero tiene otras poblaciones enclavadas en el territorio y gran número de factorías extendidas a lo largo del río hasta más de 200 kilómetros de su desembocadura.

A Gran Canaria (I, cap. V, pp. 31-34), lugar de preparación y aclimatación para su primer viaje, le dedica un capítulo entero, con un resumen breve pero completísimo de su geografía física y humana, sin olvidar añadir notas históricas, artísticas y culturales. Resulta demasiado largo para copiarlo aquí.

Desde luego, fragmentos de este tipo son abundantes, y ofrecen un equilibrio casi perfecto con las escenas de acción, las narrativas. Es quizás un acierto que ha ayudado al éxito del libro entre los lectores. Sin embargo, los elementos documentales en el plano científico aparecen, aunque variados, con cierta profusión y en algunos casos con alto valor técnico o al menos detallado. Por eso comentaremos ahora algunos de estos textos.

Aunque no abunden en exceso los textos excesivamente especializados, porque Iradier busca divulgar su aventura ante un público amplio, es cierto que quiere satisfacer también algunas exigencias científicas. Dedica así uno de los primeros capítulos (I, cap. IV, pp. 25-29), titulado «Fórmulas y métodos», a describir con interés y pasión científica los instrumentos que manejaba y las fórmulas usadas para diversas mediciones. Copiamos a continuación dos fragmentos que nos permitan apreciar este afán técnico por mostrar sus habilidades matemáticas y el tipo de instrumentación utilizado:

El movimiento del cronómetro Lozada averiguado por la observación de los pasos del Sol por el meridiano y observando la fórmula $\mathrm{m}$. = a la diferencia de las horas de ambos pasos menos la diferencia de las dos ecuaciones de tiempo partido todo por el intervalo en días, fue de $+1^{\text {s }}, 42-$. El coeficiente de temperatura lo averigüé rescatando los movimientos a diferentes temperaturas y dividiéndolos por la diferencia de temperaturas, el resultado fue $0,^{\mathrm{s}} 15$. El método que adopté para las longitudes por el cronómetro fue el de la observación de alturas correspondientes del Sol

$$
\mathrm{H}=\mathrm{C}-\mathrm{C}_{0}-\left[{ }^{\mathrm{m} /}{ }_{24}\left(\mathrm{C}-\mathrm{C}_{0}\right)\right]
$$

y en caso de estropearse el cronómetro emplearía el de las ascensiones rectas de la Luna.

$$
\text { a' Luna }-\left[\left(-\mathrm{H}_{\mathrm{m}}+\mathrm{a}_{\mathrm{m}}\right)+{ }^{\mathrm{a} /}{ }_{24}\left(\mathrm{H}_{\mathrm{m}}+\mathrm{L}\right)\right]-\mathrm{h}^{\circ} \text { Luna }
$$


Para latitudes escogí como más sencillo y de Buenos resultados, el de la altura meridiana del Sol.

$$
\zeta=\delta-\mathrm{z}=\zeta+\mathrm{a}
$$

La rectificación del quintante fue de -1'35"

$$
\text { (..) }
$$

Contaba además con un instrumento precioso que pensaba destinar a mis observaciones particulares.

Era un espectrooscopio de bolsillo a visión directa con micrómetro fotográfico dividido en ciento cincuenta partes. Con este aparato al cabo de unos días de experiencia llegué a ver distintamente en el espectro solar cincuenta y cuatro rayas que representaban el hidrógeno, el sodio, el hierro, calcio, magnesio, níquel, titanio, bario, cromo, etc. Como en la situación relativa de las rayas influye el sistema dispersivo y la naturaleza de los prismas, tuve que referirlas a la longitud de onda para obtener una escala absoluta comparable con la de otros espectros. (...) Un telémetro de prisma de Y. Molteni y Comp.a París con un objetivo de $0 \mathrm{~m}, 033$ y potencia de 15 diámetros me había de servir para la medición de distancias conocido el tamaño del punto observado y por último para apreciar detalles y croquizar puntos lejanos separé unos gemelos de campaña de 5 diámetros de amplificación y un anteojo alemán de $0 \mathrm{~m}, 034$ de objetivo (abertura libre) y al que apliqué por ocular, suprimiendo la lente colectora un stanhope muy bueno que me dio con gran éxito amplificaciones de 60 diámetros.

Iradier se convierte a través de sus fórmulas y objetos en un Robinson que acude pertrechado a su isla desierta, y nos ofrece de esta peculiar manera su retrato de explorador afanoso y preciso, que desea medirlo todo. Para los profanos en la materia resulta un sorprendente abanico de instrumentación que nos permite hacer volar la imaginación hacia la aventura que se nos promete, pues al final del capítulo, tras tanta descripción matemática e instrumental, añade con cierta ironía:

... aprendí una cosa de gran importancia.

Que era imposible que un sólo hombre con escasos recursos pudiera hacer tantas observaciones astronómicas, geológicas, zoológicas, botánicas, mineralógicas, etnológicas, barométricas, higrométricas, termométricas, atmidométricas, pluviométricas, heliométricas, ozonométricas, y nefeloscópicas porque como dijo muy bien un amigo mío:

$$
\begin{aligned}
& \text { Do el ardiente sol en las regiones } \\
& \text { Calienta con pujanza } \\
& \text { El hombre sufre tres transformaciones } \\
& \text { Sancho abarca, Sancho afloja y Sancho Panza. }
\end{aligned}
$$

También los resúmenes científicos en forma de tablas son elementos inherentes y consustanciales a la obra, especialmente en el tomo II. Por ejemplo, la tabla que describe el segundo viaje mediante los días, horas de sali- 
da y llegada y escalas recorridas (I, cap. XLV, pp. 293-295), y especialmente es significativo el conjunto de tablas extenso y detalladísimo de todas las mediciones meteorológicas imaginables recogidas durante seis meses en su primera expedición (II, cap. II, 387-446). Otras tablas son las de población (II, XVII, p. 674), los territorios españoles guineanos (II, cap. XX, pp. 739740), precios (II, VII, pp. 537-540), tribus y reyes (II, VI, pp.525-530).

No todos los textos de estilo científico son tan áridos ni tan técnicos: en su afán por transmitir conocimientos Iradier deja de vez en cuando la narración para extenderse en algún aspecto concreto, como le sucede con el fruto llamado Kola (I, cap. XII, pp. 61-63). En un capítulo completo se dedica a explicarnos el origen del fruto, su fisionomía y propiedades. Veamos sólo el comienzo, digno de aparecer como texto divulgativo en cualquier revista científica:

Cuando se llega a las costas del Gambia, llama la atención una fruta pequeña y de un color rojo encendido que es comida con avidez por los indígenas, y que se la encuentra en abundancia en los puestos de los mercados públicos, en los muelles y sobre la cubierta de los vapores. Esta fruta procede del árbol Kola acuminata Rob. Brown (Plant jav. rar. 237) cuya sinonimia botánica es Sterculia acuminata. Pal. Beauv. (Flor Owar. el Benin, 1-41-t-24); Sterculia verticillata, Schum. et Thonn. (Pl. Guinea 240); Shiponiopsis monoica, Karst, (Fl. Columb. 136 t. 69); St. Macrocarpa. Don (Gen. Syst. 1. 515). Su aspecto es bello, algo parecido al de nuestro castaño pero le excede en altura pues llega a alcanzar hasta 20 metros de elevación. Sus hojas son pequeñas y largas, 7 centrímetros de anchura por unos 25 centímetros de longitud, pero su estructura antómica es rara y sólo comparable a las del Laurus camphora. Kola, Gurú, Ombené, Nangüé, Kokoroko, etc. Son palabras diversas empleadas para nombrar la fruta de este árbol original.

En otro lugar, nos habla de la nigüa, y elabora una descripción biológica acompañada de sus propiedades venenosas y su tratamiento médico (I, cap. XXI, pp. 117-118):

La nigüa llamada disú por los vengas, es un insecto del orden de los chupadores o sifonápteros. Pules penetrante que a primera vista se confunde con una pulga. Está armada de un pico tan largo como su cuerpo con el cual abre brecha en la carne y se introduce por completo dentro de ella. Esta operación la verifica generalmente con tal cuidado que el paciente no se da cuenta de ello. Una vez dentro de las carnes se dedica a la postura y desarrollo de infinidad de huevecillos que deposita en un saco membranoso dentro del cual se coloca también la madre. Los hijuelos crecen con rapidez (...). La extracción hay que hacerla con cuidado para no romper la bolsa de las crías (...). La nigüa fija generalmente su residencia en el rodete comprendido entre la carne y uña de los dedos de los pies y aun en la planta de los mismos y muy rara vez aparece en otras partes.

Queremos incluir aquí, dentro de lo documental científico, conocimientos de otras ciencias, las llamadas sociales, pues también forman parte de la 
investigación del viajero geógrafo. Así, no sólo excursos de tipo científicotécnico toman parte en la descripción de lugares y encontramos también otros ámbitos sobre los que divulgar conocimientos.

Así, la cronología histórica aparece en algunas ocasiones, como en la preliminar «Ligera ojeada retrospectiva», un resumen cronológico de las fechas y sucesos importantes que acabaron en el comienzo del primer viaje (pp. 3-6), o la curiosa cronología personal que describe por año, mes y día todos los accesos de fiebre (pp. 656-658) que sufrió Iradier en ambas expediciones (más de ochenta), cuando trata el capítulo de las enfermedades.

Los sucesos históricos están presentes, y aparecen con regularidad al paso de distintos lugares o personajes. A veces con tintes de leyenda, y un ágil estilo sugerente en el que lo literario no deja de abrirse ya paso, se nos presentan hechos grandes y pequeños referentes a la historia del lugar que se pisa. Es el caso de la historia de los Boncoro, familia de reyes indígenas. En Satome, capital del Cabo San Juan, Iradier visita la tumba del rey Boncoro II, cuyo padre entregó su territorio a España. En época de Iradier es uno de sus hijos quien reina. Pero atendamos a algunos fragmentos de esta historia de indígenas y colonización en Guinea (I, cap. XXVI, pp. 143-144):

\begin{abstract}
La familia de los Boncoro tuvo su origen en Budipó hijo de Yikue que tomó este nombre. Budipó a quien llamaban rey de los portugueses porque comerciaba con ellos en esclavos, se estableció en Janye a 30 kilómetros al norte de Cabo San Juan. Pronto tuvo que abandonar esta comarca impulsado por la emigración de los vengas hacia el sur y llegó al Cabo de San Juan habitado entonces por la familia Bojodi con la que estableció parentesco casando una de sus hijas. A la muerte de Budipó quedó gobernando la familia su hijo Komba, quien admirado al ver un árbol gigantesco que nació y creció milagrosamente en el sitio en que habían enterrado a su padre, vaticinó desgracias y calamidades. Efectivamente: apareció en el país una banda de leopardos tan numerosa, que todos los días atacaban a los hombres sembrando el espanto y la consternación por las aldeas. (...) Los Vengas culparon a los burus (tribu del interior) de la aparición de los leopardos y esto dio motivo a una guerra cruel, espantosa que duró cuatro años. (...) [los vengas] huyeron aterrados a refugiarse en los islotes Elobey, en Corisco y Belokóbus. (...) Comba había muerto en un combate y su hermano Bane fue elegido Rey de todos los vengas con el nombre de Boncoro I y residencia en Elobey. Cuando reunió a su pueblo para anunciarle su propósito de entregar sus territorios a los españoles, hubo un gran motín (...) seguido de sus adeptos no titubeó en volver a ocupar las costas del Cabo San Juan, exponiéndose a las represalias de los burus del interior, con el fin de conseguir ser español. En efecto, en 1843 obtuvo la primera carta de nacionalidad expedida por Lerena, que guardó religiosamente entregándola a su hijo Boncoro II (...).
\end{abstract}

En el capítulo XX del tomo II (pp. 723-753), dedicado a los derechos de España sobre las colonias guineanas, Iradier hace un repaso, a través de un documento de D. José Gómez San Juan titulado Posesiones españolas en el Golfo de Guinea (1883), a la relación histórica entre España y Guinea des- 
de la conquista portuguesa en el siglo XV. Resulta ser una memoria histórica concisa de la historia política de la zona.

También la etnografía sale a relucir, en el caso que vamos a presentar acerca del uso del fetiche entre los indígenas, que trae a colación tras conocer el usado por el rey Bodumba, rey español de Elobey (I, cap. XXII, pp. 123-124). Hay que destacar cómo durante un párrafo abandona su discurso puramente descriptivo y reflexiona brevemente sobre el símbolo del fetiche respecto a la cultura occidental del momento y de su relación con la naturaleza humana:

Los pueblos salvajes, rodeados de peligros que no saben combatir de un modo racional, han buscado siempre, entre los objetos que la naturaleza les presenta, propiedades verdaderamente milagrosas que pudieran salvarlos de la muerte, cuando ésta amenazara su existencia.

Las piedras, los árboles, las planțas en general, una composición cualquiera hecha por la mano del hombre, y, en una palabra, cualquier objeto natural o artificial puede poseer la propiedad de ser amuleto o fetiche, que es compañero inseparable, protector continuo del hombre que lo lleva. La mayor parte de los pueblos ilustrados de los pueblos poco ilustrados de la tierra opinan de este modo. Nadie tiene le valor de la lucha cuando se encuentra abandonado; es preciso un amparo, un auxilio que no se explique por las leyes ordinarias, que no suceda dentro del orden natural de las cosas. En la vieja Europa, en pleno siglo XIX, pasa algo de esto.

Somos hombres y como tales adolecemos de las flaquezas y debilidades instintivas propias de nuestro modo de ser.

El fetiche puede ser cualquier objeto. Generalmente, los negros de este país usan pitones de antílope y saquitos de cuero, verdaderos depósitos de raras fruslerías $(\ldots)$

Iradier, hombre lleno de espiritualidad y fortaleza, como la mayoría de los expedicionarios del XIX, muestra en algunas ocasiones, a modo ya de incursión ensayística, reflexiones variadas, cercanas a la filosofía y a la teología. Quizá una de las más extensas y destacadas es la que dedica a algunos aspectos religiosos de los indígenas, que prologa con varias páginas de reflexión sobre Dios desde su punto de vista europeo, realizando un breve estudio comparativo en la forma de ver la religión entre occidentales e indígenas, con sus diferencias y semejanzas conceptuales (I, cap. XIX, pp. 105110). Primero hace una alabanza de Dios y a su Plan divino, y luego rectifica la idea que muchos tienen de que los indígenas son ateos. Un tanto universalista como masón, con un estilo a veces apasionado (para la propia religión), otras científicamente descriptivo (para la religión indígena) construye un texto en el que aúna ciencia y religión, como era habitual en muchos científicos de su época, admirado de las creaciones divinas:

El hombre más incrédulo siente latir su corazón helado a la vista de lo desconocido, cuando éste se presenta con todas las condiciones de la sublimidad. (...) Este algo que el hombre siente sin poderlo comprender y mucho menos expli- 
car es el Dios de todos los pueblos, es el Ser o Seres que, simbolizado en tantas formas con atributos diferentes, premia o castiga; ángel tutelar o demonio de destrucción de poder infinito que todos los hombres lo invocan, lo halagan, le piden protección; juez inexorable, espejo de la civilización y caracteres de los pueblos, que todo lo ve, que está en todos los sitios, que es dueño de todos los pensamientos y que con su gigantesca mano conduce a la humanidad por la senda de su destino. (...) El mundo civilizado tiene Dios, ser infinitamente bueno y justo, infinitamente poderoso, origen de todo lo creado. ¿Qué nos importa individualidades que no lo ven? (...) El Dios nuestro no está en los soles, ni en las nebulosas irresolubles, ni más allá. No lo vemos en el inmenso espacio vacío, no lo comprendemos en las inconmesurables distancias de este mundo sin límites, ni en los sublimes cuadros de la naturaleza, ni en las tintas del crepúsculo, ni en la tempestad, ni en el huracán, ni en el río, ni en la montaña, ni en la savia que asciende, ni en la célula, ni en el orden armónico de la naturaleza. Dios no puede verse ni con el telescopio ni con el microscopio. Dios no está en el mundo material que hemos examinado; sólo un destello de él está entre nosotros mismos, y el hombre que conoce las leyes eternas del mundo, no encontrando nada de maravilloso en sus manifestaciones, siente su manifestación divina allí, en el interior de su frente serena (...). El mundo civilizado ve a Dios en las páginas de la historia. (...) Nada en la sociedad se sale de sus vías, aunque aparentemente lo parezca. Todo marcha con la regularidad indicada por el Gran Sabio Hacedor (...). Admirable y sublime coordinación de circunstancias que impelen a la humanidad un fin señalado (...)

Veamos ahora los pueblos salvajes (...). El que ve a Dios en todas partes, aquí también lo encuentra, porque hay belleza y sublimidad, porque hay algo de grandioso y magnífico. Sin embargo de esto, si pasamos a ver los pueblos negros que habitan los bosques, nada encontramos que nos dé idea de una religión o de un culto. Ni un ídolo, ni un altar, ni un árbol sagrado, ni una oración, ni un sacrificio; y a pesar de esto, los indígenas creen en algo más que la materia bruta, admiten un principio inmortal que carece de propiedades y de necesidades físicas. El dios de los truenos, de las tempestades; el dios de los trastornos de la naturaleza, es el espíritu malo, es el demonio. (...)

Estos datos son suficientes para convencernos que este pueblo, tachado de ateo, no lo es; que adora a sus ridículos dioses con tanto fervor como nosotros al nuestro, y que su religión, lo mismo que las religiones de todos los Estados, son un freno constante que se opone al desbordamiento de las pasiones.

\section{c) Textos periodísticos: noticias, crónicas, entrevista}

La Noticia, elemento clave de un periodismo que era el comunicador de masas por excelencia a finales del siglo XIX, aparece como prueba documental cuando Iradier lo estima oportuno. Así lo hace en capítulos dedicados a las cuestiones políticas sobre Guinea, y esta muestra periodística le sirve al mismo tiempo para hacer auténticas sus declaraciones y para trasladarnos a la situación política colonial en aquel momento. Copiamos dos noticias (II, cap. XIX, p. 713 y pp. 718-719), características por otra parte de la manera de dar noticias en aquella época, incluyendo comentarios sobre el hecho por parte de la redacción. 


\title{
Le Temps, 20 de enero de 1885
}

En los círculos diplomáticos de Berlín se dice que Alemania y Francia se hallan ya de acuerdo en la determinación de sus posesiones respectivas de Batanga y el Gabón. Alemania se compromete a no pasar más allá de cierto límite en dirección al congo, y Francia a dejar a Alemania toda la libertad dentro de esta región.

\section{El Liberal, 14 de mayo de 1887}

Ha llegado a nuestra noticia que la Comisión de límites franco-española reunida en París y que se ocupa en discutir los derechos de una y otra nación en los territorios del Golfo de Guinea, no llega a ningún acuerdo, y hasta asegura que pasará dicho asunto a decisión de un árbitro.

Es de lamentar que fuera éste el resultado después de tantos meses de debates y que no se encuentre medio de llegar a ningún arreglo amistoso ni de terminar con la extraña situación en que se encuentran aquellos pueblos que pronto hará un año arbolan ambos pabellones.

Esperamos, sin embargo, que estas versiones no sean ciertas y que terminen pronto aquellas conferencias de una manera satisfactoria para ambas naciones, amigas y vecinas así en Europa como en África.

Aparece asimismo la crónica periodística (I, cap. XLIX, p.330), al citar un fragmento de El Progreso del 16 de febrero de 1885, en la que se habla de la gran conferencia organizada por la Sociedad Africanista para hacer públicos los descubrimientos de la segunda expedición de Iradier:

\begin{abstract}
La sesión $(\ldots)$ ha sido sin disputa la más solemne y brillante entre cuantas ha celebrado la Sociedad en los doce meses que lleva de existencia. El vasto salón de la Biblioteca del Círculo de la Unión Mercantil, resultaba escaso para la gran concurrencia de individuos de la Junta, de personas extrañas a la Sociedad que habían sido invitadas especialmente, y de público numeroso que se agolpaba a la puerta, ansioso de conocer en detalle las adquisiciones de territorio, que en estos últimos meses han despertado tan poderosamente la atención pública.
\end{abstract}

Aunque no esté extraída de un medio periódico, sino de un encuentro personal, el siguiente extracto de entrevista es incluido por Iradier en su preliminar «Ligera ojeada retrospectiva» (pp. 5-6) que antecede a la narración de su primer viaje. En su intención por ser quizás ajustado y respetuoso a lo que realmente se habló, y seguramente también por crear curiosidad e intensidad en el lector, que asiste casi en directo a este diálogo con el gran explorador Stanley, extraordinario africanista, utiliza un género que pasará a ser muy habitual en el periodismo:

STANLEY. El proyecto de usted es grandioso y realizable y su edad la más conveniente.

IRADIER. ¿Qué más puede hacer falta?

STANLEY. Dos cosas importantes: dinero y dinero. 
IRADIER. He calculado en veinte mil duros el presupuesto de gastos.

STANLEY. Es suficiente dada la organización que usted da a la expedición; pero, ¿cuenta usted con ellos?

IRADIER. Espero que el Gobierno de España y las Sociedades científicas del país me lo faciliten.

STANLEY. ¿Por qué no empieza usted la expedición por el Golfo de Guinea frente a las posesiones de España? (...)

d) Iconos: mapas, dibujos y fotograbados

Un elemento habitual en los relatos de viajes, y que procede del interés por dotar de forma visual inmediata a una geografía o un paisaje, son los elementos icónicos, esto es, mapas, dibujos y fotograbados.

Además de un gran mapá muy detallado de toda la zona recorrida, que se anexa al libro y es desplegable, a lo largo de África aparecen mapitas diversos, especialmente concentrados en el tomo segundo: Senegambia y Costa de Guinea (p. 87), Isleta Corisco (p. 361), Islote Elobey Pequeño (p. 365), Elobey Grande y Elobey Pequeño (p. 369), en los que se detallan los principales accidentes geográficos y poblaciones.

También encontramos dibujos y fotograbados, sobre todo en el tomo primero, y son escenas de la expedición elaboradas por el propio Iradier: caza de búfalos (p. 157), retirada de las praderas de Ukumbanguba (p. 163), Dabu-Mete (casa en que pasé mis primeras fiebres) (p. 169), un leopardo en la tienda de campaña (p. 219), ataque de Ulombe (p. 225), un jefe africano (p. 311), baile de los pamúes del Noya (p. 317), una emboscada (p. 323) y la foto del grupo de expedicionarios del segundo viaje (p. 307). Como puede apreciarse por los títulos, la mayoría de las escenas invita a evocar momentos de acción, de fuerte exotismo, como si de ilustrar una novela de aventuras se tratase, al más puro estilo de la época, al modo de un Salgari. La literariedad, la retórica un tanto fantástica de las imágenes parecen querer buscar el asombro, el interés imaginativo y la sugerencia misteriosa en el lector. Así como los mapas buscan mostrar un terreno diseñado con exactitud documental, los dibujos buscan más la sensación literaria de trasladarnos a un mundo de peligros y sucesos singulares.

Como conclusión de esta muestra tan variopinta y entremezclada de tipología textual relativa al aspecto documental del relato de viajes, podemos destacar cómo en el capítulo XIX del tomo II, dedicado a las controversias territoriales con los franceses, Iradier trae consecutivamente textos tan variados como una instancia al Ministro de Estado, su contestación, una carta de Osorio a Francisco Coello, una noticia del diario francés La Gironde, fragmentos del Diario de Osorio, una crónica del diario Porvenir Vascongado, una nota del Bulletin de la Sociéte de Géographie Comerciale de París, un 
resumen cronológico de hechos en Guinea, diversas noticias y opiniones de diarios internacionales, y todo ello intercalado en la narración crítica y comentarios personales, a modo a veces de informe y a veces de defensa, de algunos hechos importantes que muestran actuaciones o ausencias políticas españolas y confirman la potestad nacional sobre ciertos territorios.

\section{e) Enciclopedismo}

Es necesario un breve apunte acerca del tomo II de África. Su descripción sistemática de los grandes aspectos que afectan a la geografía física y humana del país del Muni, así como el repaso documental de los derechos históricos de España sobre dicho territorio le confiere sin duda alguna el grado de enciclopedia guineana en español. En la disposición de los capítulos y su desarrollo por asuntos se aprecia ese afán por reunir y sintetizar todo un mundo conocido, que contrasta con la intención más bien narrativa del primer volumen. Se puede leer, sin embargo, con parecida intensidad, en tanto que ya conocemos muchos datos relatados a través de la narración y sus excursos, y deseamos saber más sobre el lugar ya recorrido. Sólo para que sirva de referencia a lo que digo, voy a reseñar los títulos de los capítulos que conforman el volumen, aunque cada capítulo tiene a su vez algunos apartados.

El volumen está dividido en tres partes. La primera de ellas se dedica al país del Muni, a su geografía, dividida en los siguientes títulos: descripción geográfica, meteorología, producciones. La segunda parte viene dedicada al habitante del Muni, en sus siguientes aspectos: antropología, facultades, religión, estado social, agricultura-comercio, alimentación, canciones-música, idioma, industria, usos-costumbres, trajes-peinados, enfermedades, poblaciónhistoria. La tercera parte es la dedicada a demostrar los derechos históricos de España sobre el territorio guineano, con un capítulo dedicado a los documentos y contratos más recientes que lo atestiguan, un segundo capítulo dedicado a los rozamientos recientes con otras potencias coloniales y un último capítulo donde se demuestra mediante una monografía los derechos históricos de posesión territorial española en el Golfo de Guinea.

El volumen es tan variado y aglutinador como una enciclopedia e incluye descripciones, definiciones, reflexiones y críticas, crónicas históricas, documentos legales, tablas de datos muy diversos, mapas, dibujos, canciones e incluso una gramática y léxico vengas.

\section{Géneros literarios}

Iradier inicia su África con un proemio titulado «A los lectores» en el que explica sus aspiraciones de verdad (aspecto quizás por las circunstancias 
personales en las que apareció la obra es lo que más le preocupa), la falta de grandes aventuras y misterios al estilo de los relatos de Stanley, y la ausencia de pretensiones literarias. Con un estilo que vacila entre la nota aclaratoria y la humildad del proemio retórico, termina el texto, como pide el género, con una petición de disculpa por las faltas o errores y una atención a lo valioso que pueda haber en el libro, que para Iradier era la verdad documental del mismo (p. 7):

... se ruega a los lectores pasen por alto las faltas de detalle y se fijen en el conjunto que, como pocas obras de este género, tiene una cualidad apreciabilísima; la verdad.

Iradier va a preocuparse pues del dato verídico, de la prueba documental, como ya hemos visto, pero va a resultarle inevitable hacer también literatura, había de ser inherente a un soñador como él. Según señala Lily Litvak en su estudio sobre relatos de viajes exóticos (1987: 26-27) es habitual que a menudo los expedicionarios reúnan en párrafos sucesivos la descripción científica de un lugar junto con la impresión estética que les produce, creando un texto que apunta con mayor o menor calidad a lo literario. Iradier, aunque en el proemio «A los lectores» advierte que el libro «está escrito sin pretensiones literarias porque el autor no pudo nunca tenerlas», se acerca en numerosas ocasiones a lo literario, bien por buscar la estética en una descripción, bien por convertirse en un narrador ágil, vigoroso y plástico de acontecimientos y anécdotas.

Numerosas descripciones alcanzan la literariedad que no hubiera percibido un alma exclusivamente científica. Veamos cómo en una descripción de la fascinante selva africana (texto habitual de exploradores, LiLy Litvak 1987: 37 y ss.) lo informativo parece querer ser engullido por el ritmo de la exuberancia e imponencia vegetal (I, cap. XXIII, p. 130):

Las selvas africanas son la desesperación del viajero.

Sobre un terreno húmedo, blando, encharcado, compuesto de capas superpuestas de vegetales en descomposición que los siglos han ido amontonando, se elevan variedad inmensa de vegetales buscando la luz del sol y alcanzando alturas considerables. Sus ramas se entrelazan, se unen y se confunden formando una bóveda espesa de hojas variadas por su color, tamaño y figura, impenetrable a los rayos del sol y guardadora de una atmósfera densa, pesada, saturada de humedad y de venenosos miasmas que despiden un olor nauseabundo y característico muy parecido al olor de un cementerio mal cuidado. Troncos gigantescos, ramas aéreas, cadáveres monstruosos del reino vegetal derribados y medio enterrados, espesos cañaverales, ramas espinosas, tallos belludos, escamados, abigarrados, lisos como el mármol o estriados como las columnas de la antigua arquitectura, cierran el camino por todas partes (...).

En el siguiente fragmento vemos la capacidad de Iradier para describir vívidamente acciones, en este caso la carga a bordo de diversas mercancías en Bathurst (I, cap. VII, p. 42): 
El puente del vapor se convirtió en un mercado animado. Todos se movían, todos gritaban, todos se disputaban los puestos más ventajosos. De vez en cuando oleadas de negros de carne bronceada que el sudor hacía brillar se dirigían a un punto determinado dando gritos estentóreos. Era ya una cotorra que huía o un mono que deshaciéndose de sus ligaduras se encaramaba en los mástiles.

Hay muchos capítulos casi completos de narración pura, al estilo de las novelas de aventuras, especialmente entre los capítulos XXII y LXVII del tomo I. Son episodios contados en frases rápidas y cortantes, pero dramáticamente efectivas para el lector.

Las anécdotas o situaciones salpican el viaje con abundancia. A menudo surgen diálogos que nos hacen rápidos bosquejos del personaje y la situación misma. En algunas de estas anécdotas hay incluso un fondo de enseñanza o moralidad, como en la siguiente, que recuerda a una parábola con notables reminiscencias bíblicas (I, cap. XXVI, pp. 144-145):

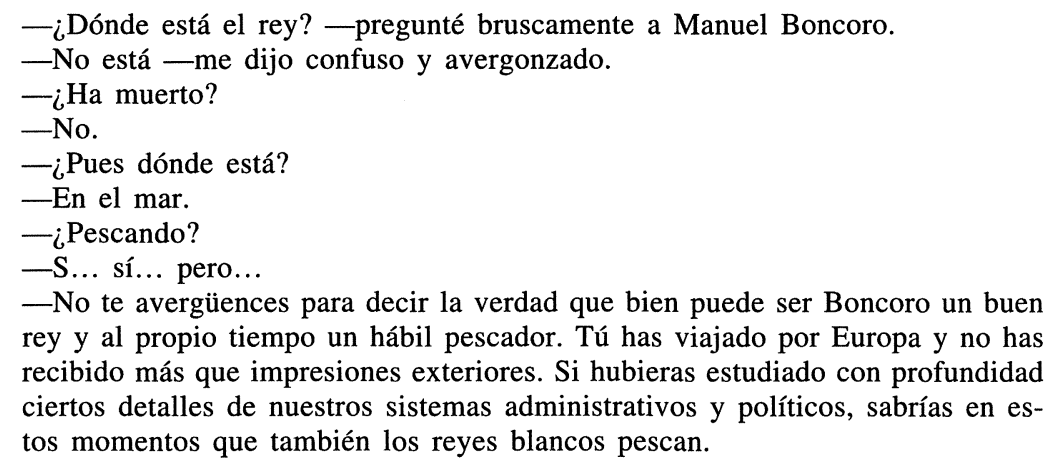

Otras adquieren la sugerencia de las leyendas y misterios (I, cap. XXV, p. 140):

Estábamos viendo el cabo San Juan (Nenye). Pero antes de pasarlo no pude menos de detenerme a observar un curioso fenómeno de los bosques. El ujinguilongo. Un gemido triste, algo parecido al del pavo, se oía por largo rato, cesando después para volver a empezar. Hubiérase dicho que eran los ayes lastimeros del moribundo que sufre crueles dolores. Mis criados me dijeron que no es más que el roce de dos bambús movidos por el viento. No estaba entonces con el ánimo de luchar con la vegetación para examinar de cerca el fenómeno y determiné examinarlo y estudiarlo en el viaje de regreso.

Dentro del género autobiográfico en el que también se inserta África destaca la aparición expresa y literal de un fragmento del diario original en el que Iradier tomaba sus notas. Es interesante este aspecto porque podemos apreciar la diferencia del material de trabajo con el que contaba y la posterior organización, desarrollo y elaboración que sufrió dicho material. En el siguiente fragmento, como en un totum revolutum, encontramos notas variadísimas de asuntos diversos, que nada tienen que ver con los fragmentos bien 
construidos que a partir de dichas notas y sus memoria nos ha dejado el expedicionario a través de sus capítulos. Veámoslo (I, cap. XXXIV, p. 191):

Entre mis papeles encuentro una Revista Militar en que hay un artículo titulado Las islas de Corisco y Annobon. Está lleno de inexactitudes.

Dice que la isla de Corisco está a tiro de fusil de Elobey, pero no explica qué clase de fusil sería el que enviase un proyectil a 20 kilómetros de distancia.

Me aseguran que en el bosque hay ciempiés de 14 pulgadas de longitud. Su mordedura es mortal.

En Elobey pequeño había antes una aldea y plantaciones de yuca. La marinería española la incendió.

El adulterio es muy común entre estos negros y continuamente se ven maridos pegando a sus mujeres por haber faltado a la fidelidad conyugal. La sífilis reina en el país aunque muy poco.

Indamu. Es un árbol de cuyas varas sacan los negros, haciendo incisiones en varios puntos, un líquido blanquecino y pegajoso con el que untan las varetas para coger pájaros. (...)

El plátano frito es mucho más indigesto que el cocido.

No sé por qué causa hay tanto gorgojo. Continuamente me estoy cogiendo de las manos, pescuezo y cara.

El jefe de los vengas de Elobey Grande se llama Bodunga.

El capítulo XLI está redactado al modo de un diario, aunque por comparación clara con el fragmento anterior se echa de ver que es elaboración literaria, como todo el engarce de textos que es África. Veamos el comienzo (p. 231):

A las cuatro de la tarde de hoy, 11 de Diciembre, se declara una tempestad horrorosa. El viento fuerte del Norte salta al Sur y se convierte en huracán. El higrómetro de Saussure marca 99. El termómetro centígrado baja a 23. La plomada y la brújula sufren perturbaciones. El agua se enfría notablemente. La lluvia que ha caído casi de un solo golpe indica en el pluviómetro 0,49 de metro; dos nimbus pasan a 900 pies ( 250 metros) de altura. La oscuridad, las descargas eléctricas, el silbido del viento y los bramidos del mar, hacen verdaderamente sublime el cuadro que presenta la naturaleza. A las seis ha terminado. Varias son las chozas que se han caído y las embarcaciones que se han ido a pique.

(...)

23 de diciembre.-Llega Elombuangani en una canoa; ha pasado durante la noche por punta Botika cantando en lengua vico.

Hay textos puramente literarios que interfieren claramente con lo documental. En el capítulo XVIII (pp. 98-99) del primer tomo se nos narran los detalles de un caso jurídico casi a modo de cuento insertado en una situación en la que un rey africano pide consejo a Iradier. Como si de un ayo Patronio moderno se tratase, y a través del filtro casi cervantino del traductor, nos cuenta el caso, una historia de amor, infidelidad y celos africanos:

El asunto que trataban en consejo según me lo tradujo el intérprete era el siguiente: 
Un buru (negro ribereño) fue con una de sus mujeres a Corisco, la que olvidándose de su marido y acordándose de un amigo corisqueño joven y bien hecho, parece que fue en su busca encontrándolo en medio de un desierto cañaveral.

El marido alarmado por la ausencia de su esposa buscó sus huellas en el blando terreno, y después de haberlas encontrado, las siguió con constancia descubriendo al fin por las yerbas pisadas en una verde pradera, que su esposa se había reunido con una persona de grandes pies y que por la doblez de las plantas holladas por ellos, parecía tener gran peso. - No había duda de ningún género; su traidora esposa había acudido a una cita; (...). Exaltado por horrible impresión, con la agudeza del instinto de la fiera se dirigió cuchillo en mano a un cañaveral vecino. Nada tan difícil como atravesar un cañaveral sin ruido. A pesar de esto, el armado marido, se arrastró como una culebra, sin doblar una hoja, sin asustar al más nervioso pajarillo, y sus ojos de lince descubrieron al fin, un cuadro digno del pincel de algún artista del valle de Pentápolis. - $-\mathrm{Su}$ primera intención fue lanzarse como un tigre para herir y matar, pero hay otra cosa mil veces peor que el arrebato en los cerebros africanos, es la venganza (...).

Pasaron en aquel matrimonio días de felicidad (...) hasta que convencido el marido de que había llegado el momento oportuno de la venganza, inventó tales historias y tan halagüeñas para su esposa, que ambos determinaron invitar al traidor amante, íntimo amigo de la familia, a pasar unos días en su casa de tierra de burus.

(...)

No cuento el final porque merece la pena leerlo. Luego, Iradier ofrece ante el consejo su versión de justicia europea, que contrasta con la más bruta africana, para conocimiento y deleite de los lectores.

Iradier inserta en su África casi todo tipo de relatos. Por ejemplo, en el capítulo XVI del tomo primero nos narra un sueño que ha tenido, un sueño que nos arrastra no sólo a cierta tradición literaria onírica de corte fantástico, sino a la idea de sueño como revelación providencial de una misión que cumplir que es, nada más y nada menos, que la de descubrir el África. Preludia, en efecto, lo que ocurrirá después. Así de literario.

Hay también textos no narrativos, argumentativos, que descubren rasgos adscritos a lo literario. Es el caso del ensayo libre, de corte humanístico, en esta ocasión de materia histórica. Nada más partir en barco hacia las Canarias, y tras observar el mar océano, nuestro explorador de quimeras reflexiona, nada más y nada menos que sobre la misteriosa Atlántida, añadiendo a las teorías que conoce su propia opinión. He aquí un fragmento de este texto al mismo tiempo expositivo y reflexivo; con cierto aire evocador y de recreación histórica, hasta alcanzar lo fantástico (I, cap. II, pp. 18-20):

Llegó un día en que terminó la felicidad del país Atlante. Sus escuadras fueron deshechas, sus ejércitos derrotados, emancipadas todas sus colonias y, como si la misión de este pueblo hubiese sido cumplida en la tierra y su existencia fuera un peligro para la humanidad, desapareció en el fondo de los mares ocultándose a los ojos de los hombres con todas sus ciudades y sus habitantes. (...) 
Que la Atlántida existió no puede dudarse; los pueblos antiguos tuvieron noticia de ella; aun más, fueron dominados por los atlantes; con ellos se batieron y las hazañas y victorias de estas luchas fueron cantadas siglos y siglos. (...) Hoy existe una cordillera que conserva el nombre de Atlas; esto y el llamarse la Etiopía Atlántida, parece indicar la vecindad con la isla de que me ocupo: además de estos datos tenemos otro que cita Platón (...). Todos estos datos inducen a creer que la Atlántida estuvo situada en el hueco comprendido entre España y las costas de África y vis a vis del estrecho de Gibraltar. (...) El estado actual de la ciencia no permite creer en la desaparición de una tan considerable cantidad de tierras en tan pocas horas sin admitir un cataclismo horroroso, un desquiciamietno estupendo, una rotura de la corteza terrestre, una lucha titánica entre el agua y el fuego de la que resultando millones y millones de metros cúbicos de gas, hicieron saltar en mil pedazos la patria de los atlantes. (...) La tierra se abrió, el mar y los restos de la Atlántida invadieron la región del fuego: éste luchó con energía, fundió las rocas, las tierras, las ciudades, el agua silvó declarándose en torrentes de vapor, atacó de nuevo la brecha, el fuego invadió el fondo de los mares (...).

Y si tratamos de evocaciones, el capítulo XIII del primer tomo, titulado «Tristeza», es una reflexión exclusivamente personal acerca del sentido de su viaje, periplo en el que él y su familia habrán de correr grandes penurias y peligros, pensando incluso cómo lloraría su muerte en caso de que la perdiera al ser atacado por un reptil durante la expedición. En un estilo íntimo, libre y sincero como corresponde a estos diálogos interiores o soliloquios, Iradier se siente existencialista (pp. 65-66):

\begin{abstract}
¿A qué pues, estar triste? La salud rebosaba por los poros de mi cuerpo, el alimento era suficiente, nada me hacía falta y sin embargo, yo notaba un vacío inmenso en mi corazón y una presión enorme en mi cerebro. Una voz, pero voz sin timbre, sin sonido, me decía: ¿A dónde vas? ¿Qué buscas? Vuelve atrás, atraviesa de nuevo los mares y cumple tu misión en los países civilizados en que naciste. El camino que sigues está lleno de abrojos y el infortunio se halla emboscado para salirte al encuentro. No eres tú solo; a ti te va unida la suerte de tus compañeras que si no las arrancaste del seno de sus familias donde nada les faltaba para ser dichosas, el cariño que te profesan es el lazo que las obliga a seguirte. Tú vas a depositarlas en una isla salvaje, vas a rodearla de todas las comunidades [sic] que están a tu alcance, pero cuando partas para el continente, ¿sabes los peligros que les esperan? En los países que vas a recorrer hay fieros antropófagos que habitan selvas inmensas y desconocidas, los tigres, los gorilas, los búfalos y las serpientes abundan cual en ninguna otra parte; asquerosos insectos y reptiles que guardan en sus mandíbulas traidor veneno (...).
\end{abstract}

Las serpientes no lo envenenaron, aunque las fiebres y algunos indígenas a punto estuvieron de matarlo en numerosas ocasiones. Pero al regreso de su primera expedición, su hija Isabela, nacida en Elobey meses antes, murió por fiebres. Esto provoca un cambio de registro en la narración de Iradier, que evoca y reflexiona al mismo tiempo, con pasión, sobre la vida después de la muerte y el inevitable grito de la Naturaleza en su lucha por sobrevivir, hasta refugiarse en Dios y su sabiduría divina. Hay momentos de 
lirismo en esta reflexión filosófica y existencial, en la que Iradier mezcla ciencia y metáfora (I, cap. XLII, pp. 238-239):

¡Cuántas veces, rendido de cansancio me he sentado en lo más inextricable de la selva y he preguntado a la Naturaleza por sus más escondidos designios! ¿Dónde está mi hija? La fe me dice que ha muerto su cuerpo; pero ella, su alma, ha empezado a vivir en un mundo de goces inefables. La razón, discutiendo sobre la justicia y bondad de Dios, confirma lo que la fe me asegura, pero la Naturaleza ¿no parece que trata de ahogar los misteriosos gritos de consuelo que nacen en el fondo de nuestro espíritu? ¿Es esto verdad? (...) La Naturaleza nos grita sin cesar que vivamos. Las lágrimas de la madre que ha perdido el ser formado en sus entrañas, el temor a la muerte engendrado en todos los seres, los movimientos instintivos de defensa en los vivos, la lucha por la existencia, las cejas defendiendo el ojo, la coraza y la piel envolviendo el cuerpo, la uña protegiendo el dedo, el cráneo blindando el cerebro, la corteza en el árbol, la púa en la flor, el veneno en el vegetal, la dureza en el mineral, la fatal atracción reteniendo a todo en su misteriosa red para que no se escape nada ni nadie de la superficie del planeta, son pruebas elocuentes de que tenemos que estar aquí y de que tenemos que vivir aquí.

Llegamos al final de este repaso variadísimo de géneros o tipología textual en África. Y con el final alcanzamos el principio, puesto que la dedicatoria de esta obra miscelánea va dirigida a la hija de Iradier, en memoria de su muerte. Y es bien original: un poema compuesto por el propio Iradier en lengua venga, y que quizás algún lector aventurero se atreva a traducir por sí solo ayudado de la lectura completa de África y del estudio de la gramática y léxico incluidos en él. Constituye lo que podríamos llamar una oda indígena guineana, un saludo a su hija ida, y que a nosotros nos sirve también de despedida:

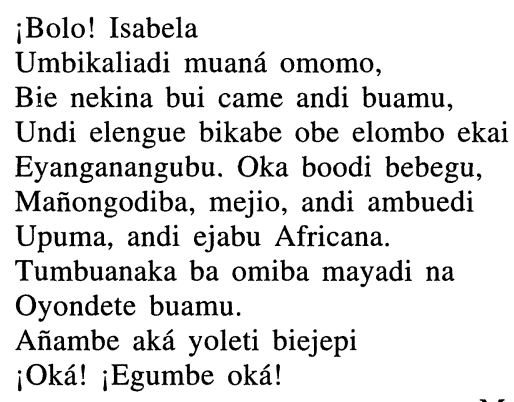

MANUEL.

\section{CONCLUSIONES}

África. Viajes y trabajos de la Asociación Eúskara La Exploradora (1887) es un relato de viajes singular y múltiple, puesto que conforma al mismo 
tiempo una memoria biográfica personal-recreada de dos exploraciones a las costas guineanas y una memoria documental-administrativa sobre las mismas. Elaborada a través del uso de géneros y tipos de texto diversos, intercalando diferentes técnicas y estilos narrativos, África puede parecer al mismo tiempo una novela de aventuras africana, unas memorias personales, un informe justificativo, una monografía temática, en una miscelánea sin par que nos ofrece una rica multiplicidad de la obra en sus temas, asuntos, narradores y puntos de vista a la vez que se logra un texto variado, ágil y de atrayente lectura, al hilo de unos acontecimientos cronológicos en torno a una misión que abarcan la aventura personal, la anécdota del viaje, la historia política colonial española de fin de siglo, los numerosos datos geográficos (físicos y humanos) de una zona exótica, las reflexiones y pensamientos al paso de lo que se halla en el camino; y mediante todo ello, con ecos de sabor enciclopédico, viajamos, veloces, pero con naturalidad, de la pluma quizás un tanto seca pero vigorosa de Iradier, desde el anecdotismo más nimio hasta el trascendentalismo más religioso.

La configuración de este atlas hecho textos asume una unidad coherente mediante la labor organizativa y al mismo tiempo creativa de documentos y experiencias, de datos y anotaciones personales, en un selvático engarce de textos y anécdotas diversos bien seleccionados, y tratado todo con un sentido de dramatismo literario que busca el ritmo de una aventura, en perfecta composición de collage. Iradier fue un hombre polifacético, y podríamos añadir que su espíritu aventurero, un tanto romántico, tenaz, junto con sus inquietudes e intereses de geógrafo multidisciplinar quedaron fielmente impresos en su África, como si hubiese querido contener en ella lo que guiaba continuamente su carrera vital, ese afán por conocer y reunir, por proyectar, un espacio en un tiempo, todo un universo para él, su anhelada Guinea llena de riquezas en un interior sin descubrir, riquezas que sólo unos pocos como él lograron apreciar en aquella época de quimeras en la que le tocó vivir. ¡Bolo! Manuel Iradier.

\section{BIBLIOGRAFÍA}

\section{Fuente primaria}

IRADIER, Manuel (1887), África. Viajes y trabajos de la Asociación Eúskara La Exploradora, Madrid, Miraguano Ediciones y Ediciones Polifemo, 1994.

\section{Fuentes secundarias}

CARrasco GonZÁlez, Antonio (2002), «Guinea en el siglo XIX. Abandono o conservación» en DíEZ TORRE, Alejandro R. (ed.), Ciencia y Memoria de África. Actas de las III Jornadas sobre "Expediciones científicas y africanismo español. 1898-1998», Madrid, Universidad de Alcalá, pp. 119-130. 
CARrizo RuEda, Sofía M. (1995), «Morfología y variantes del relato de viajes» en CARMOna FERnÁNDEZ, Fernando y MARTínez PÉrEZ, Antonia (eds.), Libros de viaje. Actas de las Jornadas sobre los libros de viaje en el mundo románico, celebradas en Murcia del 27 al 30 de noviembre de 1995, Murcia, Universidad de Murcia, 1996, pp. $119-126$.

CASTRO ANTOLÍn, Mariano de (2002), «Guinea y el africanismo español en torno a 1858» en DíEz TORRE, Alejandro R. (ed.), Ciencia y Memoria de África. Actas de las III Jornadas sobre «Expediciones científicas y africanismo español. 1898-1998», Madrid, Universidad de Alcalá, pp. 111-118.

DíEZ BORQUe, José María (1988), El comentario de textos literarios, Madrid, Playor.

Gallardo DíAz, Francisco y Romaní Alfonso, Mercé (1994), Manual práctico. Análisis y comentario de textos, Barcelona, Larousse-Planeta.

GONZÁLEZ ECHEGARAY, Carlos (2002), «Expediciones científicas a Guinea Ecuatorial (1876-1968)» en DíEz TORRE, Alejandro R. (ed.), Ciencia y Memoria de África. Actas de las III Jornadas sobre «Expediciones científicas y africanismo español. 18981998», Madrid, Universidad de Alcalá, pp. 329-338.

LITVAK, Lily (1987), El ajedrez de estrellas. Crónicas de viajeros españoles del siglo XIX por países exóticos (1800-1913), Barcelona, Laia.

MARTíNEZ SALAZAR, Ángel (1993), Manuel Iradier: las azarosas empresas de un explorador de quimeras, Barcelona, Serbal.

Moreno Gracia, Julia (2002), «La Conferencia de Berlín y el reparto colonial de África» en DíEZ TORRE, Alejandro R. (ed.), Ciencia y Memoria de África. Actas de las III Jornadas sobre "Expediciones científicas y africanismo español. 1898-1998», Madrid, Universidad de Alcalá, pp. 131-144.

MuRo, Miguel Ángel (1997), El comentario de texto: problemática, metodología y práctica, Logroño, Universidad de La Rioja.

NEGRÍN FAJARDO, Olegario (2002), «La realidad escolar en el África española. Proceso histórico de alfabetización y aculturación» en DÍEZ TORRE, Alejandro R. (ed.), Ciencia y Memoria de África. Actas de las III Jornadas sobre "Expediciones científicas y africanismo español. 1898-1998», Madrid, Universidad de Alcalá, pp. 417-438.

Pedraz Marcos, Azucena (2000), Quimeras de África. La Sociedad Española de Africanistas y colonistas. El colonialismo español de finales del siglo XIX, Madrid, Ediciones Polifemo.

REgUERA RODRíGUEZ, Antonio (2002), «La formación de la conciencia africanista en España» en DíEz TORRE, Alejandro R. (ed.) Ciencia y Memoria de África. Actas de las III Jornadas sobre "Expediciones científicas y africanismo español. 1898-1998», Madrid, Universidad de Alcalá, pp. 23-46.

Rodríguez Esteban, José Antonio (2002), «Las Sociedades Geográficas y el proceso colonial» en DíEz TORRe, Alejandro R. (ed.), Ciencia y Memoria de África. Actas de las III Jornadas sobre "Expediciones científicas y africanismo español. 1898-1998», Madrid, Universidad de Alcalá, pp. 59-74.

SierRa Delgade, Marta (2002), «Expediciones españolas en África, via siglo XIX» en DíEZ TORRe, Alejandro R. (ed.), Ciencia y Memoria de África. Actas de las III Jornadas sobre "Expediciones científicas y africanismo español. 1898-1998», Madrid, Universidad de Alcalá, pp. 317-328.

VILlAR DÉGANO, Juan F. (1995), «Paraliteratura y libros de viajes» en Compás de letras, número 7 , pp. 15-32. 


\title{
RESUMEN
}

Los viajes y trabajos de Manuel Iradier en África: género e hibridismo textual en el relato de viajes en el siglo XIX, por Álvaro Llosa Sanz.

El presente artículo analiza y sitúa el libro de viajes del siglo XIX como encrucijada de los más variados géneros. Para ello, se ha escogido el texto África. Viajes y trabajos de la Asociación Eúskara La Exploradora, escrito por Manuel Iradier en 1887 y publicado en dos volúmenes. A través de sus textos el lector va descubriendo casi enciclopédicamente un mundo que se le muestra a través del uso variadísmo de diferentes géneros textuales que se entremezclan y conforman el libro de viajes.

Palabras clave: Literatura de Viajes - Manuel Iradier - Africa - Teoría Literaria Géneros - Tipología textual.

\begin{abstract}
The present article analyzes and locates the book of trips of century xIx like a crossroad of the most varied genre. For reaching this purpose, the travel book titled África. Viajes $y$ trabajos de la Asociación Eúskara La Exploradora, written and published in two volumes by Manuel Iradier in 1887, has been chosen. Through this collection of texts the reader discovers -almost encyclopedically - an amazing world which is shown through the mixed use of different textual genres.

Keywords: Travel Literature - Manuel Iradier - Africa - Literary theory - Genre - Textual Typologhy.
\end{abstract}

